RESEARCH ARTICLE

\title{
Improvement of dermatitis by iontophoretically delivered antisense oligonucleotides for interleukin-10 in NC/Nga mice
}

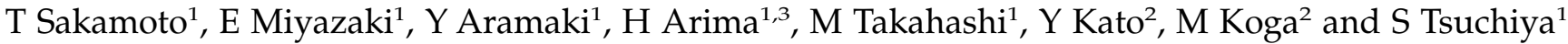 \\ ${ }^{1}$ School of Pharmacy, Tokyo University of Pharmacy and Life Science, Horinouchi, Hachioji, Tokyo, Japan; and ${ }^{2}$ Department \\ of Dermatology, Tokyo Medical University, Shinjuku, Shinjuku-ku, Tokyo, Japan
}

IL-10 is overexpressed in skin lesions of atopic dermatitis (AD) patients and believed to be an important factor in the pathogenesis of the disease. Thus the regulation of IL-10 production is a potential solution for immunotherapeutic intervention in $A D$. We examined the topical delivery of an antisense oligonucleotide for mouse IL-10 (AS6) and the therapeutic effect on the skin lesions of NC/Nga mice, a human $A D$ model. Using an iontophoresis system, about $30 \%$ of the applied dose of AS6 penetrated the skin and was distributed in the epidermis and upper dermis. Topically delivered AS6 decreased the levels of $m R N A$ and protein of IL-10 in the lesions of NC/Nga mice, with no effect on IL-4 levels. The dorsal lesions of NC/Nga mice disappeared with repeated topical application of AS6. Topically delivered AS6 showed an inhibitory effect on the production of IL-10 in the skin lesions of NC/Nga mice and had a therapeutic effect on the established dermatitis.

Gene Therapy (2004) 11, 317-324. doi:10.1038/sj.gt.3302171

Keywords: interleukin-10; antisense oligonucleotides; atopic dermatitis; NC/Nga mice; topical

\section{Introduction}

Atopic dermatitis (AD) is a chronically relapsing inflammatory disorder with pruritic and eczematous skin lesions usually associated with elevated serum IgE levels., ${ }^{1,2}$ The skin lesions of AD patients are characterized by the presence of an inflammatory infiltrate consisting of $\mathrm{T}$ lymphocytes, monocytes/macrophages, eosinophils, and mast cells. ${ }^{3,4}$ These cells are involved in the pathogenesis and development of $\mathrm{AD}$ through the release of various cytokines and chemokines including IL-4, IL-5, IL-10, IL-13, ${ }^{5}$ GM-CSF, ${ }^{6}$ and RANTES (regulated upon activation, normal T expressed and secreted). ${ }^{7}$ Of these cytokines/chemokines, IL-10 is overexpressed by monocytes/macrophages and the Th2 lymphocytes in the skin lesions of AD patients. ${ }^{8}$ In addition, IL-10 augments the production of thymus and activation regulated chemokine (TARC), which is a Th2-specific chemokine and is known for overexpression in AD lesions ${ }^{9}$ and in human keratinocytes treated by TNF- $\alpha$ and IFN- $\gamma \cdot{ }^{10}$ Furthermore, as IL-10 inhibits the apoptosis of T cells activated by ligation of T-cell receptors and IL-2 treatment, ${ }^{11}$ IL-10 may be involved in the dysregulated apoptosis of $\mathrm{T}$ cells in the skin lesions of AD. This dysregulated apoptosis is considered to be an important

Correspondence: S Tsuchiya, School of Pharmacy, Tokyo University of Pharmacy and Life Science, 1432-1 Horinouchi, Hachioji, Tokyo 192-0392, Japan

${ }^{3}$ Present address: Graduate School of Pharmaceutical Sciences, Kumamoto University, 5-1, Oe-honmachi, Kumamoto, Kumamoto 862-0973, Japan Received 07 February 2003; accepted 19 September 2003 factor in the pathogenesis of AD. ${ }^{12,13}$ Thus, IL-10 is an important factor in the pathogenesis of $\mathrm{AD}$, and the regulation of its production is a potential solution for immunotherapeutic intervention.

$\mathrm{NC} / \mathrm{Nga}$ mice are an inbred strain established from Japanese fancy mice in 1957 by Kondo (Nagoya University, Nagoya, Japan). Matsuda et al ${ }^{14}$ proposed that the NC/Nga mouse would make an excellent animal model for human AD. When kept in specific pathogen-free (SPF) conditions, ${ }^{14-16}$ the mice remain healthy. But when kept under conventional conditions, they started to scratch themselves at about 8 weeks, at which time their skin became dry and scaly. Within the next several weeks, the mice developed lesions on the ears, back, neck, and face. The lesions on the back spread from the ears down to the middle of the back and reached the posterior axillary line. Immunohistochemical examination of the lesions in conventional NC/Nga mice reveal hyperkeratosis, acanthosis, and parakeratosis, all of which resemble the typical features of the skin observed in patients with AD.,15 The lesions show lymphocyte infiltration with a high CD4/CD8 ratio, macrophage infiltration, and mast cell and eosinophil degranulation. In addition, the level of $\operatorname{IgE}$ in the blood gradually increases to high levels. ${ }^{2}$ Although these immunological, histological, and biochemical changes of $\mathrm{NC} / \mathrm{Nga}$ mice kept in conventional conditions resemble human $\mathrm{AD},{ }^{14}$ the mechanisms are not fully clear yet.

Antisense oligonucleotides (AS-ODNs) designed to hybridize specifically to heterogenous nuclear RNA or mature mRNA sequences have been shown to inhibit 
the expression of numerous genes both in vitro and in vivo. ${ }^{17,18}$ We have reported that AS6, the 18-mer phosphorothioate AS-ODN directed against the sequence in the $3^{\prime}$-untranslated region of mouse IL-10 mRNA, powerfully inhibited the production of IL-10 in RAW264.7, a mouse macrophage-like cell line, by an antisense mechanism. ${ }^{19}$ In addition, Ohmen et $a l^{8}$ revealed that the IL-10-producing cells were CD14 ${ }^{+}$ monocytes localized at the dermal perivascular infiltrate in human AD lesions. Therefore, AS6 may have potential in the treatment of AD if it can be delivered to the site of the skin where IL-10-producing cells are located. However, AS-ODNs have difficultly permeating the skin through the stratum corneum due to a lower lipophilicity and a relatively high molecular weight. To date, iontophoresis is known as a method of positively delivering ionized drugs, which enables the transdermal administration of compounds with large molecular weights. ${ }^{20,21}$ Accordingly, the method is now attracting attention as a noninvasive method, and allows AS-ODNs to penetrate the stratum corneum and be distributed in the skin. ${ }^{22}$ Thus, we expect that iontophoresis can deliver AS6 to regions where target cells are producing IL-10 in the lesions of AD. In the present study, we evaluated the therapeutic effects of topically delivered AS6 on dermatitis on the dorsal skin of NC/Nga mice, as a human AD model.

\section{Results}

\section{Cytokine and IgE levels in the skin lesion of NC/Nga mice}

$\mathrm{NC} / \mathrm{Nga}$ mice have been reported to develop eczematous skin lesions when kept in conventional surroundings ${ }^{14-16}$ but cytokine levels in the lesions of $\mathrm{NC} / \mathrm{Nga}$ mice are not reported. IL-10, IL-4, and IgE levels in the lesions were determined in mice kept under conventional and SPF conditions for different feeding periods. IL-10 and IL-4 productions increased after 8 weeks of age (Figure 1). In addition, the IgE level in the skin of conventional mice at 12 weeks of age was much higher than that of mice kept under SPF conditions (Figure 1).

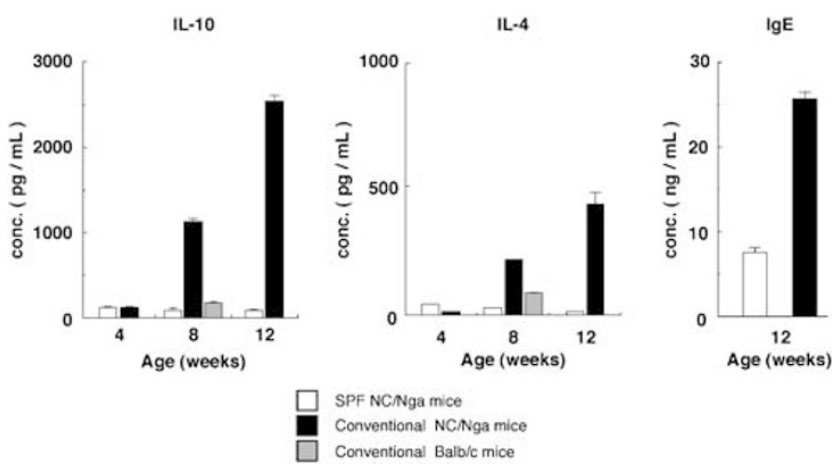

Figure 1 Determination of $I L-10, I L-4$, and IgE productions in the skin lesions of NC/Nga mice. IL-10, IL-4, and IgE productions were determined in the skin of NC/Nga mice of various ages under SPF ( $\square$ ) and conventional ( $)$ conditions. IL-10 and IL-4 productions in the dorsal skin of Balb/c mice kept under conventional conditions $(\square)$ were also determined only at 8 weeks of age. Each value represents the mean \pm s.e. for six mice in each group.

\section{Distribution and stability of AS6}

We evaluated the ability of an iontophoresis system to deliver AS6 into conventional NC/Nga mouse skin at 12 weeks of age in vivo. On topical application of $1 \mu \mathrm{Ci}$ of [ $\left.{ }^{32} \mathrm{P}\right]-\mathrm{AS} 6$ with iontophoresis, approximately $30 \%$ of the dose was observed in the skin under the cathodal gel, while about $35 \%$ remained in the cathodal gel (Figure 2a). Only a negligible level of radioactivity was observed in the anodal gel, the skin under it, and other tissues. On the other hand, no radioactivity of $\left[{ }^{32} \mathrm{P}\right]-\mathrm{AS} 6$ was observed in the skin under the cathodal gel when current was not applied (data not shown).

To evaluate the localization of AS6 in the skin, skin was cross-sectioned after iontophoresis of AS6 labeled with rhodamine (Rho) at the $5^{\prime}$ end (Rho-AS6). Fluorescence of Rho was observed at the epidermis and upper dermis, and iontophoresis allowed Rho-AS6 to penetrate the stratum corneum although Rho-AS6 remained in the stratum corneum (Figure $2 \mathrm{~b}$, IP $(+))$. On the other hand, no fluorescence was observed in the stratum corneum, when no current was applied (Figure $2 b, \mathrm{IP}(-)$ ).

To check the stability of AS6 in the skin of $\mathrm{NC} / \mathrm{Nga}$ mice, AS6 was extracted from the skin following iontophoresis and subjected to gel electrophoresis. In Figure 2c, radioactivity gave a single band at the same mobility as a marker, [ $\left.{ }^{32} \mathrm{P}\right]-\mathrm{AS} 6$ (18 mer) (lane 1). The
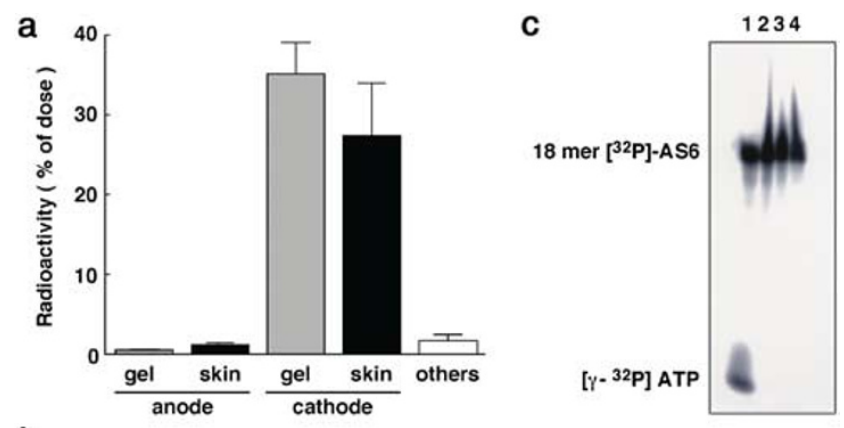

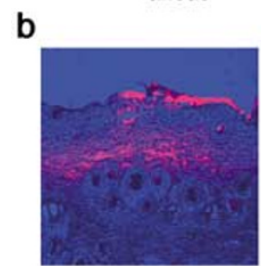

$\mathbf{I P}(+)$

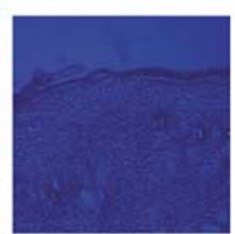

IP(-)
Figure 2 Distribution and stability of topically delivered AS6 in NC/Nga mice. [ $\left.{ }^{32} \mathrm{P}\right]-A S 6$ was applied at $20 \mathrm{nmol}$ including $1 \mu \mathrm{Ci}$ in the cathodal gel. Iontophoresis was carried out under conventional conditions $(10 \mathrm{~V}$, $0.3 \mathrm{~mA}, 2.5 \mathrm{~h}$ ) in NC/Nga mice. (a) Radioactivity recovered after topical application of $\left[{ }^{32} \mathrm{P}\right]-A S 6$ with iontophoresis. Others included blood, liver, spleen, and kidney. Each value represents the mean \pm s.e. for six mice in each group. (b) Cross-sections showing the distribution of Rho-AS6 in NC/ Nga mouse skin. Rho-AS6 was applied at $20 \mathrm{nmol}$ in the cathodal gel. Fluorescent images were obtained immediately after application using confocal laser scanning microscopy. IP $(+)$, iontophoresis was carried out; IP (-), iontophoresis was not carried out. Similar results were obtained in three separate experiments. (c) The stability of $\left.{ }^{32} P\right]-A S 6$ in the skin of NC/ Nga mice. Lane 1, mixture of intact 18 mer [ $\left.{ }^{32} \mathrm{P}\right]-A S 6$ and $\left[\gamma_{-}{ }^{32} \mathrm{P}\right]-A T P$; lane 2, immediately; lane 3, 24 h; lane 4, $48 \mathrm{~h}$ after topical application of $\left[{ }^{32} \mathrm{P}\right]-A S 6$. The intactness of the oligonucleotide in the skin was quantitated as follows: the intactness of the oligonucleotide (\%)= $\left\{\right.$ (radioactivity of the band corresponding to $\left[{ }^{32} \mathrm{P}\right]-A S 6$ (18 mer) on the gel)/(whole radioactivity extracted from skin after $\left[{ }^{32} \mathrm{P}\right]-A S 6$ iontophoresis) $\} \times 100$. All mice used were at 12 weeks of age. 
band intensities of AS6 extracted from the skin immediately (lane 2), $24 \mathrm{~h}$ (lane 3), and $48 \mathrm{~h}$ (lane 4) after iontophoresis were about 90,85 , and $80 \%$ of $\left[{ }^{32} \mathrm{P}\right]-\mathrm{AS} 6$ distributed in the skin, respectively. In the case of $24 \mathrm{~h}$ after iontophoresis, quantitation of intactness of AS6 in the skin was carried out three times, and the average intactness was $85.21+2.60 \%$.

\section{Effects of AS6 on cytokine and IgE levels in the skin lesion}

Next, we studied the ability of AS6 to inhibit the production of IL-10 in the skin lesions of NC/Nga mice at 12 weeks of age. Various amounts of AS6 were applied with iontophoresis $(10 \mathrm{~V}, 0.3 \mathrm{~mA}, 2.5 \mathrm{~h})$ and cytokine levels in the skin lesions were measured at $24 \mathrm{~h}$ after the iontophoresis. The IL-10 production was not affected by $5 \mathrm{nmol}$, but when mice were treated with 20 or $40 \mathrm{nmol}$ AS6, the IL-10 levels were reduced to $70 \%$ of the control that was treated with buffer solution (Figure 3a). On the other hand, no change in IL-4 levels was observed irrespective of the concentration of AS6 (Figure 3a). We also examined the change in IL-10 protein level versus time following treatment with $20 \mathrm{nmol}$ of AS6. The inhibitory effect of AS6 on IL-10 protein production reached a maximum at $24 \mathrm{~h}$ and was attenuated at $48 \mathrm{~h}$ (Figure 3b, AS6). Compared with the protein levels, the IL-10 mRNA level normalized to $\beta$-actin mRNA level decreased promptly after treatment and reached 32, 27, and $28 \%$ of that in mice iontophoretically treated with buffer solution (Cont.) at 6, 12, and $24 \mathrm{~h}$ after treatment. The level was $59 \%$ of the control even at $48 \mathrm{~h}$ (Figure 3c). In contrast, the random phosphorothioate oligonucleotides (S-ODNs), R6, had no inhibitory effect on IL-10 protein and mRNA levels throughout this study (Figure $3 b$ and $c)$.

To determine whether repetitive AS6 administration augments and sustains the inhibitory effect on IL-10 production, treatment with AS6 was carried out four times, with a $2.5 \mathrm{~h}$ iontophoretic treatment applied every 3 days (72 h intervals) over the course of 11 days. In Figure 3, IL-10 protein levels in skin lesions decreased during the experimental period (up to $48 \mathrm{~h}$ ) after AS6 treatment. Because we predicted any alleviative alteration in skin lesions came after downregulation of IL-10 protein with AS6 treatment, 3 days was set out as the interval time in this experiment. By the treatment of AS6, the IL-10 level decreased to $50 \%$ of control mice that were treated with buffer (Figure 4, Cont.: $1844.77 \pm 75.83 \mathrm{pg} /$ $\mathrm{ml}$ versus AS6 treated: $894.24 \pm 96.36 \mathrm{pg} / \mathrm{ml})$, but IL-4 level did not change by the treatment with AS6 (Figure 4). The IgE level also decreased to $80 \%$ of the control value after treatment with AS6 (Figure 4, Cont.: $19.41 \pm 0.65 \mathrm{ng} / \mathrm{ml}$ versus AS6 treated: $15.85 \pm 1.47 \mathrm{ng} / \mathrm{ml})$

\section{Effect of AS6 in animal model of atopic dermatitis}

To examine whether AS6 could cure the lesions of NC/ Nga mice, the dorsal lesions in mice kept under conventional conditions for 12 weeks were treated with $20 \mathrm{nmol}$ of AS6 three times with iontophoresis over the course of 8 days with 3 days intervals (Figure 5a). Skin lesions, such as erythema, inflammation, scaling, and erosion on the back, observed at day 1 almost disap- a

IL-10

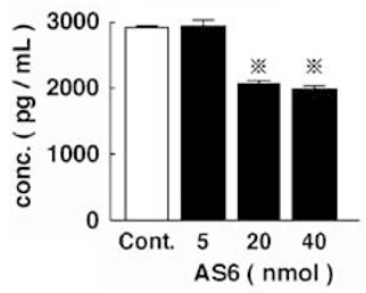

b

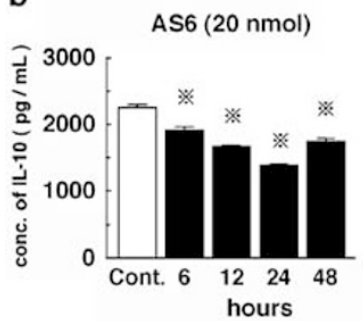

C
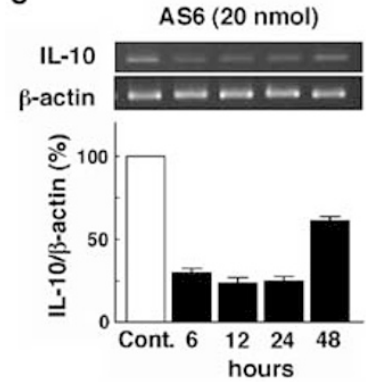

IL-4

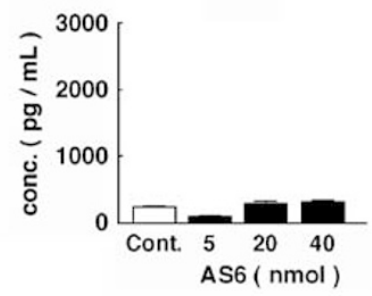

$\mathrm{R} 6(20 \mathrm{nmol})$
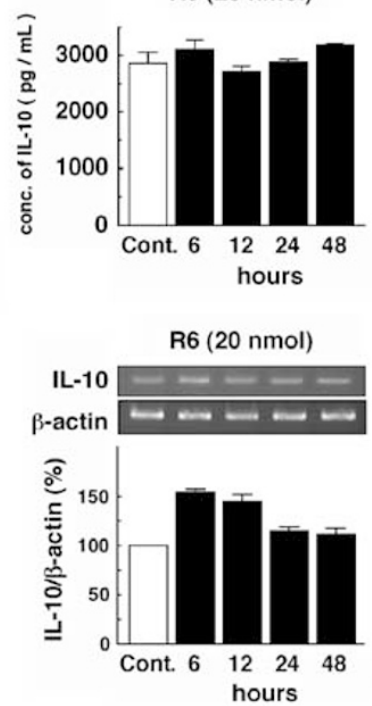

Figure 3 Effects of AS6 on IL-10 production in the skin lesions of conventional NC/Nga mice. (a) Effect of AS6 dose on IL-10 production in the skin lesions of NC/Nga mice. AS6 was topically applied at the indicated amounts in the cathodal gel, and the levels of cytokines in the skin were determined $24 \mathrm{~h}$ later as described in Materials and methods. Significant difference from the value in mice treated with buffer solution (Cont.), $※ P<0.05$. (b) Time course of the level of IL-10 protein in the skin lesions of NC/Nga mice after topical application of AS6 and R6. Each value represents the mean \pm s.e. for six mice at 12 weeks of age in each group. Significant difference from the value in mice without treatment (Cont.), $※ P<0.05$. (c) Time course of the level of IL-10 mRNA in the skin lesions of NC/Nga mice after topical application of AS6 and R6. AS6 or R6 was applied at $20 \mathrm{nmol}$ in the cathodal gel. The graphs represent the relative band intensities (\%) of IL-10 normalized to $\beta$-actin as compared with no treatment (Cont.) and the results are shown as mean + s.e. for three mice in each group. The levels of IL-10 protein and mRNA in the skin were determined at the indicated time after the application as described in Materials and methods. All mice used were at 12 weeks of age.

peared by day 8 following treatment (Figure 5a). In contrast, satellite skin lesions distant from the application site such as on the face or ears were not repaired. In addition, no effects were observed in the mice treated with R6 (Figure 5a). Clinical scores of the mice treated with AS6 also decreased significantly $(P<0.0001)$ from those of the control and with R6 (Figure 5b). On histological analysis at day 8, the lesions of the skin after R6 treatment showed hyperkeratosis, parakeratosis, acanthosis, and exocytosis in the epidermis (Figure 5c, R6). In contrast, the lesions showed extensive regression in the epidermis after AS6 treatment (Figure5c, AS6), which looked similar to the skin of $\mathrm{NC} / \mathrm{Nga}$ mice under SPF conditions (data not shown). 

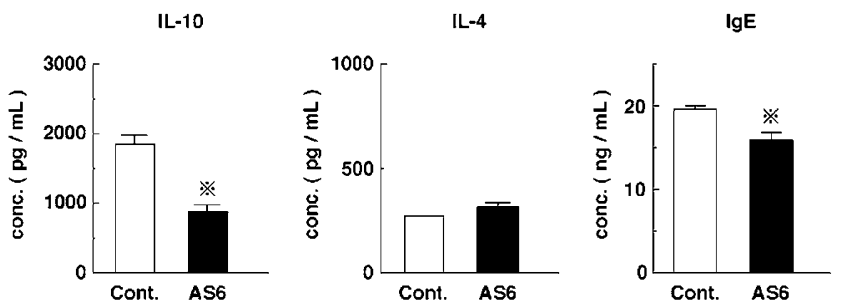

Figure 4 Effects of repetitive AS6 administration on IL-10, IL-4, and IgE production. AS6 was topically applied at 20 nmol four times every 3 days (72 $\mathrm{h}$ intervals) in conventional NC/Nga mice at 12 weeks of age, and the levels of cytokines and IgE in the treated skin were determined $24 \mathrm{~h}$ after the last application as described in Materials and methods. Each value represents the mean \pm s.e. for six mice in each group. Significant difference from the value in mice treated with buffer solution (Cont.), $P P<0.05$.

a

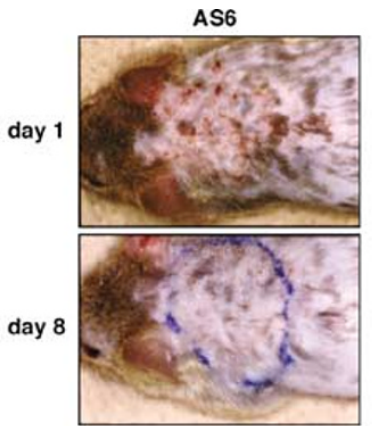

b

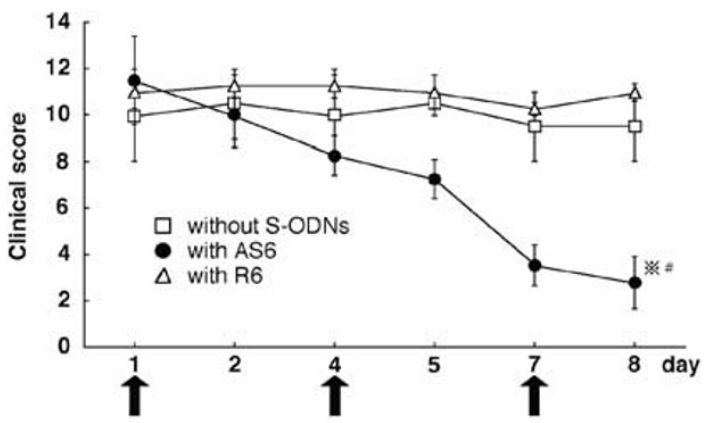

C

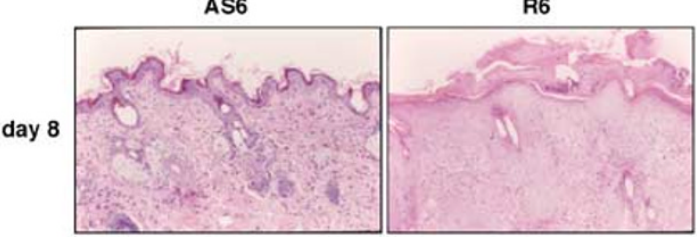

Figure 5 Clinical observations and clinical scores of the skin lesions after topical application of AS6. AS6 or R6 was topically applied at $20 \mathrm{nmol}$ three times every 3 days (72 $\mathrm{h}$ intervals) in conventional NC/Nga mice at 12 weeks of age. (a) Day 1, before the application of AS6 or R6; day 8, $24 \mathrm{~h}$ after the last application of AS6 or R6. The results shown are representative of three mice in each group. (b) Clinical scores of mice treated with AS6 $(\bullet)$ or R6 $(\triangle)$ were calculated as described in Materials and methods. The clinical score of the control mice treated with buffer not including S-ODNs ( $\square$ ) was also determined. Each value represents the mean \pm s.e. for six mice in each group. Arrows indicate timing of iontophoresis treatment with buffer, AS6, or R6. Significant difference, $※$, from without $S-O D N s(P<0.0001)$; \#, from with R6 $(P<0.0001)$. (c) Hematoxylin and eosin staining after repeated topical application of AS6 or R6. At $24 \mathrm{~h}$ after the last application (day 8), the treated skin was resected, cut into 6- $\mu m$ sections, stained, and examined by light microscopy for histologic changes. The results shown are representative of six mice in each group.

\section{Discussion}

Immunological disturbances have been noted in the affected skin of patients with $\mathrm{AD}$, caused by the overexpression of various cytokines and chemokines, such as IL-4, IL-5, IL-10, IL-13, and GM-CSF. ${ }^{23}$ Of these cytokines/chemokines, IL-10 is overexpressed predominantly by monocytes but possibly also by skin-infiltrating $\mathrm{T}$ lymphocytes in the lesions of human $\mathrm{AD}$, as compared with IL-4, IL-5, and IL-13. ${ }^{8}$ These observations suggest that the regulation of IL-10 expression is a potential solution for immunotherapeutic intervention in AD. In the present study, we examined the therapeutic effect of topically delivered AS6, an AS-ODN for IL-10, on the skin lesions of $\mathrm{NC} / \mathrm{Nga}$ mice, as a human $\mathrm{AD}$ model.

For AS6 delivery into NC/Nga mice skin, we chose PDP iontophoretic method because this ensured high current density for long application time and enabled transdermal and transmucosal administration of ionized drugs with large molecular weight. ${ }^{20,21}$ Figure $2 \mathrm{a}$ and $\mathrm{b}$ shows that PDP iontophoresis could deliver about $30 \%$ of AS6 in whole epidermis and upper dermis with the stratum corneum in NC/Nga mice. It was reported that phosphorothioate oligonucleotides seem to interact with some molecular species of the stratum corneum (eg intracellular keratin). ${ }^{24}$ Therefore, this nature may decrease the penetration of the AS6 into epidermis and upper dermis; nevertheless, it may be believed that the AS6 concentration is enough to inhibit IL-10 production. On the other hand, only low radioactivity was observed in the anodal gel, the skin under it, and other tissues (blood, liver, spleen, and kidney). Although AS6 might distribute in other tissues (eg small intestine, urine), ${ }^{25}$ radioactivities of these tissues were not determined.

PDP iontophoresis appeared to be more suited for the delivery into the skin in terms of less skin irritation by a depolarization circuit to remove the current accumulated on the skin surface. The skin responses such as erythema and irritation during iontophoresis are known as major side effects of iontophoresis. Anigbogu et al ${ }^{26}$ reported that no significant skin irritation was observed in the current density applied range $0.1-1.0 \mathrm{~mA} / \mathrm{cm}^{2}$ for $1 \mathrm{~h}$ using $0.9 \% \mathrm{w} / \mathrm{v} \mathrm{NaCl}$ and $0.5 \mathrm{~mA} / \mathrm{cm}^{2}$ for up to $4 \mathrm{~h}$ in rabbits. In human, it has been shown clinically that current densities $\leqslant 0.5 \mathrm{~mA} / \mathrm{cm}^{2}$ were well tolerated. ${ }^{27}$ Similarly, we could not observe in this study any symptoms such as erythema, sore, and irritation in $\mathrm{NC} / \mathrm{Nga}$ mice. Therefore, current density $0.3 \mathrm{~mA} /$ $2.5 \mathrm{~cm}^{2}$ in this study was well tolerated in $\mathrm{NC} / \mathrm{Nga}$ mice skin.

NC/Nga mice have been reported to develop eczematous skin lesions when kept in conventional surroundings but not under SPF conditions. ${ }^{14}$ As shown in Figure 1, the levels of IL-10, IL-4, and IgE increased in proportion to the duration of time that $\mathrm{NC} / \mathrm{Nga}$ mice were kept under conventional conditions. The increased IL-10 level was reduced by topical application of AS6, with no effect on the IL-4 level (Figure 3a). In some cases, antisense oligonucleotides exert inhibitory effects nonspecifically via binding to proteins with their phosphorothioate backbone. In this study, however, it was shown that AS6, but not R6, had inhibitory effects on IL-10 mRNA and protein productions without an effect on IL-4 production in NC/Nga mice skin lesions (Figure 3). 
It was also shown that treatment with AS6 improved the skin lesions, but R6 did not (Figure 5). R6 is a phosphorothioate oligonucleotide of the same base length and composition as AS6. If these inhibitory effects of AS6 depended on a nonspecific binding to some proteins via phosphorothioate backbone, R6 must be able to improve the skin lesions. This result suggested that AS6 had brought out the inhibitory effects by targetspecific, RNase H-dependant mechanism, that is 'antisense mechanism'. On the other hand, R6 increased the IL-10 mRNA level at early time after treatment (Figure 3c). Although this increase might result from a nonspecific effect, the reason is not known. In addition, the inhibitory effect of AS6 in the skin lesion lasted at least $48 \mathrm{~h}$ (Figure $3 \mathrm{~b}$ ). The duration of effectiveness of AS6 is consistent with stability in the skin as shown in Figure 2c.

It has been reported that IL-10 protein was localized in large oval cells resembling monocytes in the dermal perivascular infiltrate of atopic lesions, ${ }^{8,28}$ and the number of dermal macrophages in atopic lesions of $\mathrm{NC} / \mathrm{Nga}$ mice increased when compared with nonlesional skin. ${ }^{9}$ Leung et $a l^{29}$ reported that macrophages were the predominant inflammatory cells in chronic AD lesions. Furthermore, it was recently demonstrated that engagement of FceRI, a high-affinity receptor for $\operatorname{IgE}$, with $\operatorname{IgE}$ and anti-IgE antibodies, induces the production of IL-10 in human monocytes. ${ }^{30}$ Thus, it is speculated that AS6 was taken up by monocytes/macrophages that had been infiltrated in skin lesions and inhibited IL-10 production by these cells in NC/Nga mice. As our previous report ${ }^{19}$ showed, AS6 at 10-20 $\mu \mathrm{M}$ caused a $50 \%$ reduction in IL-10 production by RAW264.7 cells stimulated with $10 \mu \mathrm{g} / \mathrm{ml}$ of LPS. It is then to be expected that the concentration of AS6 around target cells would reach at least $10 \mu \mathrm{M}$ in the skin from the following findings. In Figure 2a, 30\% of applied AS6 $(20 \mathrm{nmol})$ was distributed in the skin region. Thus, approximately $6 \mathrm{nmol}$ of AS6 was topically transferred in the skin $\left(2.5 \mathrm{~cm}^{2}\right)$ under the cathodal gel following iontophoresis, and more than $80 \%$ of this was intact after $48 \mathrm{~h}$ (Figure $2 \mathrm{c})$. As calculated from tissue volume $(65 \mu \mathrm{l} /$ $\mathrm{cm}^{2}$ for the viable skin tissue ${ }^{24}$ ), the concentration of intact AS6 within the skin was about $29.5 \mu \mathrm{M}$ $\left(20 \mathrm{nmol} \times 30 \% \times 80 \% / 65 \mu \mathrm{l} \times 2.5 \mathrm{~cm}^{2}\right)$, including AS6 trapped in stratum corneum. This concentration might be enough to have an inhibitory effect on IL-10 production in the skin.

In this study, the suppression of IL-10 production by topical application of AS6 alleviated the skin lesions of NC/Nga mice (Figure 5). Currently, on the other hand, topical applications of corticosteroids and tacrolimus (FK-506) are commonly used to treat AD, through immunosuppressive effects that are based on the inhibition of NF- $\mathrm{KB}$ activation. ${ }^{31,32}$ In addition, Nakamura et $a l^{33}$ reported that a single topical delivery of $N F-\kappa B$ decoy ODNs significantly regressed atopic dermatitis in $\mathrm{NC} / \mathrm{Nga}$ mice. TARC is the primary chemokine in ADlike lesions of $\mathrm{NC} / \mathrm{Nga}$ mice, ${ }^{9}$ and TARC serum levels are closely related to disease activity in human AD. ${ }^{34}$ Furthermore, TARC production was regulated by both IL-10 and NF- $\kappa$ B, the former enhances IFN- $\gamma-$ and TNF- $\alpha-$ induced TARC production ${ }^{10}$ and the latter is a crucial transcription factor in TARC expression. ${ }^{35}$ These facts allow us to speculate that the inhibition of IL-10 by AS6 may lead to the decrease in TARC production in skin lesions and result in the improvement of dermatitis at the application site of conventional NC/Nga mice. Further work is in progress to confirm the mechanism(s) of the improvement by AS6.

In conclusion, we demonstrated that the inhibition of IL-10 production by topically delivered AS6 showed a therapeutic effect on established dermatitis of a human AD model, the NC/Nga mouse. These results are sure to facilitate the treatment of $\mathrm{AD}$, as well as shed light on the causes of the disease. However, it remains to be clarified how the precise mechanism(s) in the healing of skin lesions results from the inhibition of IL-10 production by AS6.

\section{Materials and methods}

\section{Mice}

Male NC/Nga mice (4-12 weeks old) housed under SPF or conventional conditions and male Balb/c mice $(8$ weeks old) housed under conventional conditions were purchased from SLC Co., Ltd (Shizuoka, Japan). Animal use and relevant experimental procedures were approved by the Tokyo University of Pharmacy and Life Science Committee on Care and Use of Laboratory Animals.

\section{Chemicals and reagents}

$\gamma$-[32P]-ATP was obtained from Daiichi Pure Chemicals (Tokyo, Japan). Proteinase $\mathrm{K}$ and DNase I were purchased from Nippon Gene (Toyama, Japan). All other chemicals and solvents were of analytical reagent grade. All antibodies used in this study were purchased from PharMingen (San Diego, CA, USA).

\section{Oligonucleotides}

All S-ODNs and oligonucleotide primers for RT-PCR purified by high-performance liquid chromatography were purchased from Amersham Pharmacia Biotech (Tokyo, Japan). AS6, an antisense S-ODN directed against the $3^{\prime}$-untranslated region of IL-10 mRNA, and R6, an S-ODN with 13 mismatches relative to AS6, are 5'AGG TCC TGG AGT CCA GCA-3' (AS6 target position, 637-654 of the IL-10 gene) and 5'-ATG CGC GAG TAC GCG TAC-3', respectively. AS6 labeled with Rho at the $5^{\prime}$ end (Rho-AS6) was also purchased from Amersham Pharmacia Biotech. All S-ODNs were dissolved in distilled milli-Q water.

\section{Radiolabeling of AS6}

AS6 was labeled at the $5^{\prime}$ end using a $5^{\prime}$-end-labeling kit (MEGALABEL, Takara, Tokyo, Japan) including T4 polynucleotide kinase and $\gamma-\left[{ }^{32} \mathrm{P}\right]-\mathrm{ATP}$ according to the manufacturer's directions. [ $\left.{ }^{32} \mathrm{P}\right]$-labeled AS6 ([32P]-AS6) was purified using Microcon-3 (Amicon, Tokyo, Japan) and then a QIAquick Nucleotide Removal Kit (QIAGEN, Tokyo, Japan). The [ $\left.{ }^{32} \mathrm{P}\right]-\mathrm{AS} 6$ was checked by electrophoresis and the radiochemical purity was $>99 \%$. The specific radioactivity was $3.6 \mu \mathrm{Ci} / \mathrm{nmol}$.

\section{Iontophoretic delivery of S-ODNs}

Hair on the dorsal skin of mice was shaved $24 \mathrm{~h}$ before application of S-ODNs. Agarose gel (1\% (w/v) in $100 \mu \mathrm{M}$ Tris-HCl buffer, $\mathrm{pH} 7.5,18 \mathrm{~mm}$ (diameter) $\times 1.2 \mathrm{~mm}$ 
(thickness)) containing $20 \mathrm{nmol}$ or $1 \mu \mathrm{Ci}$ of S-ODNs was placed on one skin lesion from the neck to the middle of the back and a cathode $(\mathrm{AgCl})$ was set on the gel. The same volume of agarose gel $(1 \%(\mathrm{w} / \mathrm{v})$ in a $0.45 \% \mathrm{NaCl}$ solution, $18 \mathrm{~mm}$ (diameter) $\times 1.2 \mathrm{~mm}$ (thickness)) was placed on the middle to bottom of the back and an anode (Ag) was set. Each electrode was connected to a Hisamitsu ADIS4030 power supply (Hisamitsu Pharmaceutical Co., Tokyo, Japan) run in the pulse depolarized mode. Repetitive application of S-ODNs was carried out on the same dosal skin site with 3 days interval. Iontophoresis of S-ODNs was carried out with a constant voltage of $10 \mathrm{~V}$, constant current of $0.3 \mathrm{~mA}$, frequency of $40 \mathrm{kHz}$, and duty of $30 \%$ for $2.5 \mathrm{~h}$ (conventional conditions). By adding a resister looped in, constant current of $0.3 \mathrm{~mA}$ must be kept during iontophoresis.

\section{Extraction of S-ODNs from skin}

Following iontophoresis of $\left[{ }^{32} \mathrm{P}\right]-\mathrm{AS} 6$, the skin under the cathodal gel (diameter, $18 \mathrm{~mm}$ ) was excised and transferred into $2 \mathrm{ml}$ of DNA extraction buffer (0.5\% SDS, $10 \mathrm{mM} \mathrm{NaCl}, 20 \mathrm{~mm}$ Tris-HCl, and $10 \mathrm{~mm}$ EDTA, pH 7.6). Samples were homogenated with a Polytron homogenizer (Kinematica AG, Tokyo, Japan) for $5 \mathrm{~min}$ and then proteinase $\mathrm{K}$ solution (final concentration, $1 \mathrm{mg} / \mathrm{ml}$ ) was added to the homogenates. After an incubation at $55^{\circ} \mathrm{C}$ for $4 \mathrm{~h}$, the homogenates were mixed with an equal volume of phenol/chloroform $(1: 1 \mathrm{v} / \mathrm{v})$ and centrifuged at $12000 \mathrm{~g}$ and $4^{\circ} \mathrm{C}$ for $20 \mathrm{~min}$. Then the upper (aqueous) fractions were mixed with a half-volume of chloroform and centrifuged. The upper fractions were mixed with 2.5 times the volume of ethanol, and the precipitates obtained by centrifugation were used as total ODN.

\section{Biodistribution and stability of AS6 in the skin}

For analyzing the biodistribution of [32P]-AS6 in the skin and other tissues (blood, liver, spleen, and kidney), each tissue was removed and dissolved in Soluene-350 tissue solubilizer (Hionic-Fluor, Packard, Tokyo, Japan). Samples were subsequently radioassayed after the addition of scintillant (Hionic-Fluor, Packard). Radioactive counts were obtained with an Aloka-3000 liquid scintillation counter (Aloka, Tokyo, Japan). For analyzing the stability of AS6 in skin, the total ODN, as described above, was subjected to polyacrylamide gel electrophoresis on a $20 \%$ $(\mathrm{w} / \mathrm{v})$ gel. The gel was dried and the radioactivity was examined using a BAS-2000 (Fujifilm, Tokyo, Japan). We quantitated the intactness of the oligonucleotide in the skin using the following formula: the intactness of the oligonucleotide $(\%)=\{$ (radioactivity of the band corresponding to $\left[{ }^{32} \mathrm{P}\right]-\mathrm{AS} 6$ (18 mer) on the gel)/(whole radioactivity extracted from skin after $\left[{ }^{32} \mathrm{P}\right]-\mathrm{AS} 6$ iontophoresis) $\} \times 100$.

\section{Determination of IL-10, IL-4, and IgE}

The levels of cytokines and $\operatorname{IgE}$ in the skin were determined by ELISA. Following iontophoresis, the skin under the cathodal gel (18 $\mathrm{mm}$ in diameter) was resected, and homogenated with the Polytron homogenizer in $2 \mathrm{ml}$ of saline containing protease inhibitors $(0.17 \mathrm{mg} / \mathrm{ml}$ PMSF, $0.02 \mathrm{mg} / \mathrm{ml}$ leupeptin, and $0.01 \mathrm{mg} / \mathrm{ml}$ aprotinin). The homogenate was centrifuged at $2200 \mathrm{~g}$ for $3 \mathrm{~min}$ and the supernatant was collected. The levels of IL-10, IL-4, and IgE in the supernatant were assayed by a sandwich ELISA using pairs of purified capture and biotinylated detection antibodies recognizing murine IL10 (JES5-2A5 and SXC-1 biotin), IL-4 (11B11 and BVD624G2 biotin), and IgE (R35-72 and R35-92 biotin), respectively, according to the manufacturer's protocols. The recoverability of IL-10, IL-4, and IgE in the supernatant of the homogenate and lack of proteolysis was confirmed using their recombinants.

\section{$R T-P C R$ analysis}

Total RNA was isolated from the skin by a guanidinium isothiocyanate procedure. ${ }^{36}$ Briefly, the dorsal skin (under a cathodal gel) was homogenized in $2 \mathrm{ml}$ of ISOGEN solution (Nippon gene, Toyama, Japan). Chloroform $(0.2 \mathrm{ml})$ was then added to the homogenate, and the mixed suspension was centrifuged at $12000 \mathrm{~g}$ and $4^{\circ} \mathrm{C}$ for $15 \mathrm{~min}$. The total RNA was recovered in the aqueous phase, and precipitated by an addition of 2-propanol. After centrifugation, the pellet was washed once with $80 \%$ ethanol, dried, and resolved in $10 \mu \mathrm{l}$ of diethyl pyrocarbonate-treated water.

cDNA was synthesized by reverse transcription. Approximately $2.5 \mu \mathrm{M}$ of random primer (9 mer, Takara Bio Inc., Shiga, Japan) was annealed to $1 \mu \mathrm{g}$ of total RNA and extended with $200 \mathrm{U}$ of SuperScript II reverse transcriptase (Gibco BRL, Gaithersburg, MD, USA) in $20 \mu \mathrm{l}$ of a reaction buffer containing $2 \mu \mathrm{l}$ of first strand buffer and $2.5 \mu \mathrm{l}$ of deoxyribonucleotide triphosphates (dNTPs, $2.5 \mathrm{mM}$ each) for $50 \mathrm{~min}$ at $42^{\circ} \mathrm{C}$.

PCR amplification was carried out in a TaKaRa PCR Thermal Cycler MP (Takara Bio Inc., Shiga, Japan). PCR was conducted in a total volume of $25 \mu \mathrm{l}$ with $0.5 \mu \mathrm{l}$ of cDNA, $0.75 \mu \mathrm{M}$ of the upper and lower primers, $0.5 \mathrm{mM}$ of the dNTPs, and $2.5 \mathrm{U}$ of TaKaRa Ex Taq DNA polymerase. The following primers were used: for IL10, 5'-GGA CAA CAT ACT GCT AAC CGA CTC-3' (upper, 258-281) and 5'-AAA ATC ACT CTT CAC CTG CTC CAC -3' (lower, 490-513); for $\beta$-actin, 5'-GCA CCA CAC CTT CTA CAA TGA G-3' (upper, 180-201) and 5'TTG GCA TAG AGG TCT TTA CGG A-3' (lower, 788809). The thermal cycling conditions were set to $94^{\circ} \mathrm{C}$ for 2 min, followed by 33 cycles (for IL-10) or 27 cycles (for $\beta$-actin) of amplification at $94^{\circ} \mathrm{C}$ for $2 \mathrm{~min}, 55^{\circ} \mathrm{C}$ for $1.5 \mathrm{~min}$, and $72^{\circ} \mathrm{C}$ for $1 \mathrm{~min}$ for denaturing, annealing, and extension. After the last cycle, the samples were incubated at $72{ }^{\circ} \mathrm{C}$ for $10 \mathrm{~min}$. The amplified products were separated on $1.5 \%$ agarose gels by electrophoresis and visualized with $0.1 \%$ ethidium bromide under UV light. Band intensities were analyzed with NIH Image software.

\section{Histological analysis}

The dorsal skins were resected, embedded in Tissue-Tek OTC compound (Miles Inc., Elkhart, IN, USA), and snapfrozen in liquid nitrogen. The tissue was then cut by a cryostat into $6-\mu \mathrm{m}$ sections, stained with hematoxylin and eosin, and examined by light microscopy for histological changes. To analyze the distribution of Rho-AS6 in the skin, the dermal skin was fixed with $10 \%$ formalin for $16 \mathrm{~h}$ at $4^{\circ} \mathrm{C}$, embedded, snap-frozen, and cut as described above. The sections were examined by confocal laser scanning microscopy (Micro-Radiance, Bio-Rad Laboratories Inc., Tokyo, Japan). 


\section{Clinical scoring of skin lesions}

A total clinical severity score for skin lesions was calculated as the sum of individual grades of the strength score as 0 (none), 1 (mild), 2 (moderate), and 3 (severe) times the affected area score as 0 (none), $1(\sim 1 / 3), 2$ $(\sim 2 / 3)$, and $3(\sim 1)$ for each skin lesion (erythema, inflammation, scaling, and erosion).

\section{Statistical analysis}

Data are given as the mean \pm s.e. The statistical significance of mean comparisons was determined by ANOVA with Duncan's test for multiple comparison. The $P$-values for significance were set at 0.05 . In studying the clinical scoring of skin lesions in NC/Nga mice, the significance of mean comparisons was determined by two-way ANOVA.

\section{Acknowledgements}

We are grateful to Miss Misaki Matsuda, Miss Shiho Yamaoka, and Mr Takahiro Wada for technical assistance. We are also grateful to Hisamitsu Pharmaceutical Co., Ltd for supplying the iontophoretic apparatus ADIS4030.

\section{References}

1 Cooper KD. Atopic dermatitis: recent trends in pathogenesis and therapy. J Invest Dermatol 1994; 102: 128-137.

2 Rudikoff D, Lebwohl M. Atopic dermatitis. Lancet 1998; 351: 1715-1721.

3 Soter NA. Morphology of atopic eczema. Allergy 1989; 44 (Suppl 9): 16-19.

4 Uehara M, Izukura R, Sawai T. Blood eosinophilia in atopic dermatitis. Clin Exp Dermatol 1990; 15: 264-266.

5 Grewe $\mathrm{M}$ et al. A role for Th1 and Th2 cells in the immunopathogenesis of atopic dermatitis. Immunol Today 1998; 19: 359-361.

6 Pastore $\mathrm{S}$ et al. Granulocyte macrophage colony-stimulating factor is overproduced by keratinocytes in atopic dermatitis. Implications for sustained dendritic cell activation in the skin. I Clin Invest 1997; 99: 3009-3017.

7 Ying $S$ et al. The kinetics of allergen-induced transcription of messenger RNA for monocyte chemotactic protein-3 and RANTES in the skin of human atopic subjects: relationship to eosinophil, T cell, and macrophage recruitment. J Exp Med 1995; 181: 2153-2159.

8 Ohmen JD et al. Overexpression of IL-10 in atopic dermatitis. Contrasting cytokine patterns with delayed-type hypersensitivity reactions. J Immunol 1995; 154: 1956-1963.

9 Vestergaard $\mathrm{C}$ et al. Overproduction of Th2-specific chemokines in NC/Nga mice exhibiting atopic dermatitis-like lesions. J Clin Invest 1999; 104: 1097-1105.

10 Vestergaard C et al. IL-10 augments the IFN-gamma and TNFalpha induced TARC production in HaCaT cells: a possible mechanism in the inflammatory reaction of atopic dermatitis. J Dermatol Sci 2001; 26: 46-54.

11 Cohen SB et al. Interleukin-10 rescues $\mathrm{T}$ cells from apoptotic cell death: association with an upregulation of Bcl-2. Immunology 1997; 92: 1-5.

12 Orteu $\mathrm{CH}$ et al. The inhibition of cutaneous $\mathrm{T}$ cell apoptosis may prevent resolution of inflammation in atopic eczema. Clin Exp Immunol 2000; 122: 150-156.

13 Akdis $\mathrm{M}$ et al. Cytokine network and dysregulated apoptosis in atopic dermatitis. Acta Odontol Scand 2001; 59: 178-182.
14 Matsuda $\mathrm{H}$ et al. Development of atopic dermatitis-like skin lesion with IgE hyperproduction in NC/Nga mice. Int Immunol 1997; 9: 461-466.

15 Vestergaard C, Yoneyama $\mathrm{H}$, Matsushima K. The NC/Nga mouse: a model for atopic dermatitis. Mol Med Today 2000; 6: 209-210.

16 Matsumoto $\mathrm{M}$ et al. IgE hyperproduction through enhanced tyrosine phosphorylation of Janus kinase 3 in NC/Nga mice, a model for human atopic dermatitis. J Immunol 1999; 162: 1056-1063.

17 Agrawal S, Zhao Q. Antisense therapeutics. Curr Opin Chem Biol 1998; 2: 519-528.

18 Crooke ST. Antisense therapeutics. Biotechnol Genet Eng Rev 1998; 15: $121-157$.

19 Arima $\mathrm{H}$ et al. Specific inhibition of interleukin-10 production in murine macrophage-like cells by phosphorothioate antisense oligonucleotides. Antisense Nucleic Acid Drug Dev 1998; 8: 319-327.

20 Merino V, Kalia YN, Guy RH. Transdermal therapy and diagnosis by iontophoresis. Trends Biotechnol 1997; 15: 288-290.

21 Guy RH. Iontophoresis - recent developments. J Pharm Pharmacol 1998; 50: 371-374.

22 Regnier V, Preat V. Localization of a FITC-labeled phosphorothioate oligodeoxynucleotide in the skin after topical delivery by iontophoresis and electroporation. Pharm Res 1998; 15: 1596-1602.

23 Kay $\mathrm{AB}$ et al. Messenger RNA expression of the cytokine gene cluster, interleukin 3 (IL-3), IL-4, IL-5, and granulocyte/ macrophage colony-stimulating factor, in allergen-induced latephase cutaneous reactions in atopic subjects. J Exp Med 1991; 173: 775-778.

24 Regnier V, De Morre N, Jadoul A, Preat V. Mechanisms of a phosphorothioate oligonucleotide delivery by skin electroporation. Int J Pharm 1999; 184: 147-156.

25 Brand RM, Hannah TL, Norris J, Iversen PL. Transdermal delivery of antisense oligonucleotides can induce changes in gene expression in vivo. Antisense Nucleic Acid Drug Dev 2001; 11: $1-6$.

26 Anigbogu A et al. An in vivo investigation of the rabbit skin responses to transdermal iontophoresis. Int J Pharm 2000; 200: 195-206.

27 Burnette RR, Ongpipattanakul B. Characterization of the pore transport properties and tissue alteration of excised human skin during iontophoresis. J Pharm Sci 1988; 77: 132-137.

28 Leung DY. Atopic dermatitis: the skin as a window into the pathogenesis of chronic allergic diseases. J Allergy Clin Immunol 1995; 96: 302-318; quiz 319.

29 Leung DY, Bhan AK, Schneeberger EE, Geha RS. Characterization of the mononuclear cell infiltrate in atopic dermatitis using monoclonal antibodies. J Allergy Clin Immunol 1983; 71: 47-56.

30 Novak N, Bieber T, Katoh N. Engagement of Fc epsilon RI on human monocytes induces the production of IL-10 and prevents their differentiation in dendritic cells. J Immunol 2001; 167: 797-804

31 Nakagawa $\mathrm{H}$ et al. Tacrolimus ointment for atopic dermatitis. Lancet 1994; 344: 883 .

32 Hiroi J et al. Effect of tacrolimus hydrate (FK506) ointment on spontaneous dermatitis in NC/Nga mice. Jpn J Pharmacol 1998; 76: $175-183$.

33 Nakamura $\mathrm{H}$ et al. Prevention and regression of atopic dermatitis by ointment containing NF-kB decoy oligodeoxynucleotides in NC/Nga atopic mouse model. Gene Therapy 2002; 9: 1221-1229.

34 Kakinuma T et al. Thymus and activation-regulated chemokine in atopic dermatitis: serum thymus and activation-regulated chemokine level is closely related with disease activity. I Allergy Clin Immunol 2001; 107: 535-541. 
35 Berin MC, Eckmann L, Broide DH, Kagnoff MF. Regulated production of the $\mathrm{T}$ helper 2-type T-cell chemoattractant TARC by human bronchial epithelial cells in vitro and in human lung xenografts. Am J Respir Cell Mol Biol 2001; 24: 382-389.
36 Chomczynski P, Sacchi N. Single-step method of RNA isolation by acid guanidinium thiocyanate-phenol-chloroform extraction. Anal Biochem 1987; 162: 156-159. 